\title{
Regional lung densities in alpha-1 antitrypsin deficiency compared to predicted values
}

\author{
Berend C. Stoel ${ }^{1 *} \mathbb{D}$, Jan Stolk ${ }^{2}$, M. Els Bakker ${ }^{1}$ and David G. Parr ${ }^{3}$
}

\begin{abstract}
Background: We developed a method to calculate a standard score for lung tissue mass derived from CT scan images from a control group without respiratory disease. We applied the method to images from subjects with emphysema associated with alpha-1 antitrypsin deficiency (AATD) and used it to study regional patterns of differential tissue mass.

Methods: We explored different covariates in 76 controls. Standardization was applied to facilitate comparability between different CT scanners and a standard Z-score (Standard Mass Score, SMS) was developed, representing lung tissue loss compared to normal lung mass. This normative data was defined for the entire lungs and for delineated apical, central and basal regions. The agreement with $D_{L C O} \%$ pred was explored in a data set of 180 patients with emphysema who participated in a trial of alpha-1-antitrypsin augmentation treatment (RAPID).
\end{abstract}

Results: Large differences between emphysematous and normal tissue of more than 10 standard deviations were found. There was reasonable agreement between SMS and $D_{L C O} \%$ pred for the global densitometry $(K=0.252, p<0.001)$, varying from $\mathrm{K}=0.138$ to $\mathrm{K}=0.219$ and $0.264(p<0.001)$, in the apical, central and basal region, respectively. SMS and $\mathrm{D}_{\mathrm{LCO}} \%$ pred correlated consistently across apical, central and basal regions. The SMS distribution over the different lung regions showed a distinct pattern suggesting that emphysema due to severe AATD develops from basal to central and ultimately apical regions.

Conclusions: Standardization and normalization of lung densitometry is feasible and the adoption of the developed principles helps to characterize the distribution of emphysema, required for clinical decision making.

Keywords: Computed tomography, Emphysema, Image analysis, Outcome measures, Standardization

\section{Background}

Chronic obstructive pulmonary disease (COPD) is defined physiologically using spirometric measurement of forced expiratory volume in $1 \mathrm{~s}\left(\mathrm{FEV}_{1}\right)$, forced vital capacity (FVC) and the ratio of $\mathrm{FEV}_{1} / \mathrm{FVC}$ [1]. Pulmonary emphysema is frequently present in patients with COPD and may be assessed by measuring the diffusing capacity for carbon monoxide $\left(\mathrm{D}_{\mathrm{LCO}}\right)$, which reflects the emphysematous tissue destruction that leads to loss of alveolar structure and, as specifically reflected in the $\mathrm{D}_{\mathrm{LCO}}$, the pulmonary vascular bed [2]. The time course of $\mathrm{D}_{\mathrm{LCO}}$ and

\footnotetext{
* Correspondence: b.c.stoel@lumc.nl

'Division of Image Processing, Department of Radiology, Leiden University Medical Center, Leiden, The Netherlands

Full list of author information is available at the end of the article
}

$\mathrm{FEV}_{1}$ decline as physiologic parameters of emphysema progression is highly variable between (and within) patients and they correlate poorly [3]. Although $\mathrm{D}_{\mathrm{LCO}}$ is considered to reflect emphysema severity in patients with COPD, emphysema is defined in histopathological rather than physiological terms [4] and a more disease-specific parameter, obtained from lung densitometry using computed tomography $(\mathrm{CT})$, was introduced 40 years ago [5, 6], and validated against histopathological standards by three different laboratories [7-9]. Lung densitometry was also validated by relating densitometry to clinically relevant measures [10-13]. It was found to be more consistent over time as compared to $\mathrm{FEV}_{1}$ and $\mathrm{D}_{\mathrm{LCO}}$ [14], most probably because densitometry is a more direct measurement of emphysema and intrinsically effort 
independent. In patients with emphysema associated with alpha-1-antitrypsin deficiency (AATD), $\mathrm{D}_{\mathrm{LCO}} / \mathrm{VA}$ predicted all cause and respiratory mortality. However, CT densitometry consistently proved to be the best independent predictor of mortality [15]. Some years later, the European Medicines Agency (EMA) approved phase II and III randomized controlled clinical trials to study the effect of new drug treatments on emphysema and, in 2007, the United States Food and Drug Administration (FDA) accepted the methodology for use as an outcome measure in trials of disease modifying therapy in AATD patients. In 2015, the EMA approved a license for Respreeza on the basis of a beneficial treatment effect demonstrated using lung CT densitometry [16-18]. As post-hoc analysis, regional densitometry has been introduced to study emphysema progression and treatment effects in the apical, central and basal regions of the lungs [19-21] to improve insight into pathophysiology and local emphysema treatment planning.

The clinical application of lung densitometry, however, has not followed the pace of its application in clinical research. To date, there is no international accepted database with reference values obtained from individuals with healthy lungs and no standardized CT image acquisition protocol for lung densitometry. Moreover, we currently lack adequate standardization between different CT manufacturers (despite calibration for water and air), correction of lung density for differences in lung sizes between subjects and for inspiration levels [22].

The aim of our study was to develop an integrated method to report lung density in terms that would address the above obstacles and facilitate the introduction of the methodology into routine clinical practice [23].

\section{Methods}

\section{Overview}

We considered that to express CT lung density as "percent predicted density" values would require: 1) a recalibration method for compensating for differences between CT scanners; 2) a comparison with normal values from a database, producing a standard score; and 3) a method to correct for volume differences within and between subjects (see Fig. 1).

First, all CT data from normal controls were analyzed by lung densitometry (Fig. 1a), producing for each subject the lung volume during $\mathrm{CT}$ scanning and a

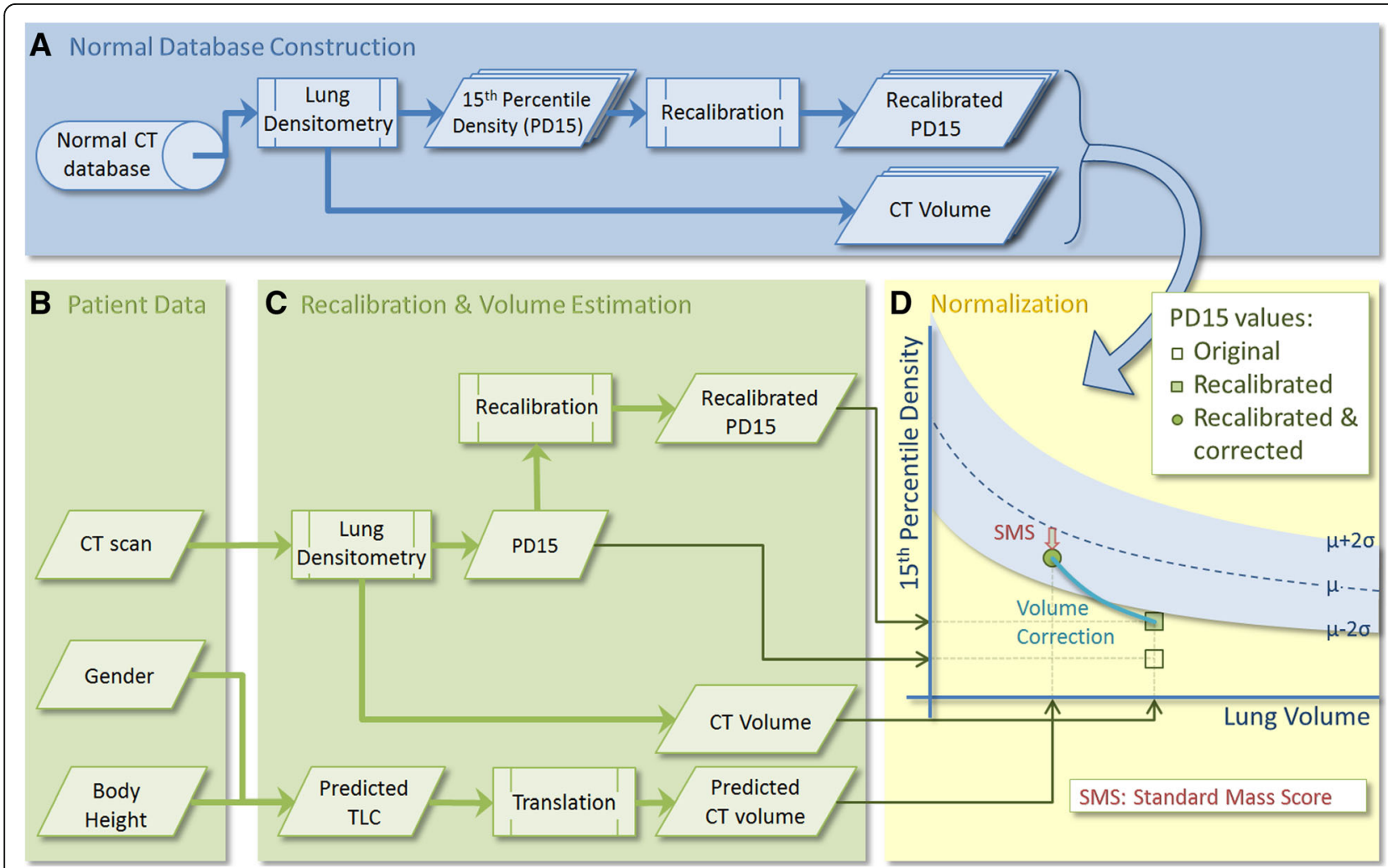

Fig. 1 Overview of the proposed integrated method. a Construction of the normal database, producing lung volumes and recalibrated density values from a normal population; $\mathbf{b}$ Input data from an emphysema patient to be evaluated; c Calculation of recalibrated density data and predicted CT lung volume of a patient; $\mathbf{d}$ Normalization and volume correction of the density values, resulting in a Z-score for lung tissue mass: Standard Mass Score (SMS). In this particular example, a seemingly abnormally low lung density (PD15) can actually fall within the normal range for tissue mass, after accounting for different CT scanners (i.e. recalibration of lung density values) and lung volumes (volume correction) 
recalibrated density value, 15 th percentile density (PD15). From this database, the mean relation between lung size (volume) and PD15 in the normal population was determined, along with the standard deviation in density at each volume.

A standard score for a particular patient was produced from CT imaging, together with gender and body height (Fig. 1b). This CT scan was analyzed by densitometry software, to produce a lung CT volume and a recalibrated PD15 value (Fig. 1c). In the same step, the predicted total lung capacity (TLC) was calculated (based on gender and body height) and translated into a predicted lung CT volume, which is needed because of the difference in definition between 'physiologically' measured TLC and 'anatomically' measured CT-volume, the latter of which is defined as the total number of voxels in the lungs, excluding the trachea but including parenchyma and small vessels. In the final step (Fig. 1d), a so-called standard mass score (SMS) was calculated, based on the normal density database and the patient's lung volume and recalibrated density values. Volume correction was applied based on the predicted CT volume.

In addition to these global measurements, the same approach was followed for regional lung densitometry, where the apical, central and basal regions of the lungs were analyzed separately [19]. To define these areas, the lungs were divided vertically into 12 equivolumetric partitions and the superior and inferior partition were omitted, as they contain artifacts, e.g. partial volume effects [20]. The separate regions were determined by combining the remaining partitions (apical:3, central:3, basal:4). The above normalization was also applied to these separate regions in the normal database, producing three regional standard mass scores; i.e. $\mathrm{SMS}_{\text {apical }}, \mathrm{SMS}_{\text {central }}, \mathrm{SMS}_{\text {basal }}$.

A detailed description of the different components is presented in the following sections.

\section{Lung densitometry}

All CT data were analyzed by a software package Pulmo, version 2.1 (Medis specials, Leiden, the Netherlands), using a threshold of $-380 \mathrm{HU}$ to detect both lungs, with exclusion of the trachea [22]. From this segmentation result, the density distribution was calculated and lung density was measured as the 15th percentile density ${ }^{1}$ (PD15; the threshold density in gram/liter, at which $15 \%$ of lung voxels have a lower density). By summing all included lung voxels, the lung volume (CT-volume) was determined.

\section{Normal CT database}

CT scans from 76 subjects (52 males, 24 females, see Table 1) without respiratory symptoms, who had been screened for pulmonary metastases following treatment of osteosarcoma, were reviewed by a radiologist and, if a normal radiological appearance was observed, the subjects
Table 1 Characteristics of the normal subjects [24] and AATD patients [16]

\begin{tabular}{lll}
\hline & Normals & AATD \\
\hline Subjects [n] & 76 & 180 \\
Age [years] & $44.5(11.8)$ & $53.1(7.4)$ \\
Sex $[\mathrm{M} / \mathrm{F}]$ & $52 / 24$ & $98 / 82$ \\
$\mathrm{BMI}\left[\mathrm{kg} / \mathrm{m}^{2}\right]$ & $25(3)$ & $26(4)$ \\
$\mathrm{FEV}_{1}[\%$ pred] & $93(4)$ & $47(12)$ \\
$\mathrm{FEV}_{1}$ NC & $0.87(0.08)$ & $0.44(0.11)$ \\
DLco $_{\text {LCpred] }}$ & $95(10)$ & $55(19)$ \\
\hline
\end{tabular}

were checked for normal spirometry and gas transfer, as reported in an earlier study [24]. In this population, $\mathrm{FEV}_{1}$ (standard deviation, SD) and $\mathrm{D}_{\mathrm{LCO}}(\mathrm{SD})$ was $93(4) \%$ and 95(10) \% of predicted values, respectively. Of these subjects, 16 were current smokers, 26 were ex-smokers and 34 were never-smokers. Age ranged between 26 and 78 years. The CT data were acquired using a Philips AVE-U scanner (Phillips Medical Systems, Eindhoven, the Netherlands) at full inspiration and were used to create a database of normal values (normal database). The CT scanner was calibrated as recommended by the manufacturer using a standardized image acquisition protocol (at $140 \mathrm{kVp}, 40 \mathrm{mAs}$, pitch factor $2,7 \mathrm{~mm}$ collimation, reconstructed with a slice thickness of $7 \mathrm{~mm}, 5 \mathrm{~mm}$ increment and reconstruction filter 4 [24]). CT images were analyzed, and both lung volume and PD15 values were stored in a database.

To identify those variables required for normalization, the influences of several parameters on percentile density were explored in this normal database, by linear regression using log-transformed percentile density as response variable. The potential explanatory variables included gender, smoking status, age, log-transformed CT-volume and inspiration level, defined as the log ratio of CT-volume and predicted total lung capacity (TLC). Data were analyzed with SPSS 16.0 (SPSS Inc., Chicago, IL) and a stepwise variable selection was applied. Age, smoking status and gender were excluded from the model, as they did not significantly explain additional variation. The model with only CT-volume and inspiration level fitted best to the data $\left(R^{2}=0.65\right)$.

Therefore, lung size and inspiration level were used for normalization of PD15 values from patients, performed in three steps, as discussed in the following three sections: 1) recalibration of density values; 2) correction for inspiration level; and 3) comparison with the normal database with lung size as covariate.

\section{Recalibration}

Percentile density values were recalibrated to account for differences that occur between different $\mathrm{CT}$ scanner types 
and manufacturers despite routine calibration for air and water. In an internal recalibration method, all density values were rescaled during image analysis, using the mean air density sampled outside of the patient (above the sternum) as a reference value for air [25]. The mean density measured in the descending aorta was used as a reference for the density of blood (rescaled to $1050 \mathrm{~g} / \mathrm{L}$ ) [22].

\section{Volume correction}

Correction for variation in inspiratory level has been explored using several methods and adapted for use in drug evaluation trials [11]. For analyzing data from single time points, only a physiological method can be used, referred to as the 'sponge model'. In this model, differences in inspiratory level are considered to be mass-preserving, i.e. lung mass remains constant during the respiratory cycle, as in a dry sponge that is compressed then released [26, 27]. As a result, lung volume and density are linearly related when both are log transformed, with a slope of exactly -1 . Consequently, this linear relation is used to correct for differences in inspiratory level, by calculating the percentile density that would apply if the patient had inhaled to his/her predicted total lung capacity $\left(\mathrm{TLC}_{\mathrm{pred}}\right)$. In contrast to pulmonary function tests, however, patients are scanned in the supine position and, by definition, CT-volume includes lung tissue and excludes tracheal air, whereas TLC is a measure of total air volume without lung tissue, but including tracheal air. Therefore, the predicted $\mathrm{CT}$-volume $\left(\mathrm{V}_{\mathrm{CT} \text {,pred }}\right)$ was estimated from the predicted TLC values from the normal population by linear regression, separating for gender. The resulting coefficients for intercept and slope, $\gamma$ and $\delta$, respectively, were then used to translate between predicted TLC and predicted CT-volumes.

Because of image reconstruction errors, possible physiological influences and the fact that the PD15 is used instead of the mean density values, the 'sponge model' does not apply exactly in practice [28], therefore a steeper slope (S) of - 1.1 was used, obtained from optimizing the reproducibility of the volume correction, using the baseline inspiratory and expiratory scans of the RAPID trial.

In short, the corrected percentile density value, $\rho_{\text {cor }}$ was defined as:

$$
\rho_{\text {cor }}=\rho_{\text {cal }} \cdot\left(\frac{V_{C T, p r e d}}{V_{C T}}\right)^{S}=\rho_{\text {cal }} \cdot\left(\frac{\gamma+\delta \cdot T L C_{\text {pred }}}{V_{C T}}\right)^{S}
$$

where $\rho_{\text {cal }}$ is the recalibrated percentile density value, $\mathrm{V}_{\mathrm{CT}}$ and $\mathrm{V}_{\mathrm{CT} \text {,pred }}$ are the observed and predicted lung volume in CT, respectively, and $\mathrm{TLC}_{\text {pred }}$ the percent predicted value according to the ERS standard, based on body height and gender [29]. The coefficients $\gamma$ and $\delta$ are the intercept and slope from linear regression, respectively, to translate TLC predicted values to normal CT volumes.

\section{Normalization}

For the final step, the recalibrated and volume-corrected percentile density was compared to the database of normal values from an earlier study [24], the raw data of which is made available in the Additional file 1. To account for differences in lung size, data were corrected based on the linear relation between log-transformed volume and log-transformed density. To indicate the 'percent predicted density' for a particular patient, the standard score (Z-score) was calculated, defined by the difference between the measured percentile density and the predicted value (derived from the normal database) at the patient's lung CT volume, divided by the residual standard deviation after linear regression.

Pulmonary emphysema is characterized by a reduction in lung mass (due to tissue loss and reduced blood volume in pulmonary capillaries). The use of volume-corrected data reflects the loss of tissue mass alone compared to the normal database and may be referred to as the 'Standard Mass Score' (SMS).

An SMS of 0 is equivalent to normal tissue mass ("100\% predicted"). A value between -2 and 0 indicates a decreased lung tissue mass that is still within the normal range, and a value between 0 and 2 indicates a normal but increased tissue mass. All SMS values above 2 or below -2 indicate an abnormal increased or decreased lung tissue mass, respectively.

Thus, the recalibrated and volume-corrected standard mass score was defined as:

$$
\begin{aligned}
S M S & =\frac{\log \left(\rho_{c o r}\right)-\left(\alpha+\beta \log \left(V_{C T, \text { pred }}\right)\right)}{\sigma} \\
& =\frac{\log \left(\rho_{\text {cor }}\right)-\left(\alpha+\beta \log \left(\gamma+\delta T L C_{\text {pred }}\right)\right)}{\sigma},
\end{aligned}
$$

where $\log \left(\rho_{\text {cor }}\right)$ and $\alpha+\beta \cdot \log \left(\mathrm{V}_{\mathrm{CT} \text {,pred }}\right)$ are the measured and predicted log percentile density values, respectively, $\alpha$ and $\beta$ are the intercept and slope from the regression line between log volume and log percentile density from the CT scans of normal subjects, and $\sigma$ is the residual standard deviation after linear regression.

\section{AATD CT database}

Baseline CT scans were selected from the RAPID clinical trial database (see Table 1 ), described previously $[16,17]$. 
In this study, patients aged 18-65 years were included with serum AAT levels below $11 \mu \mathrm{M}$ and $\mathrm{FEV}_{1}$-values $\geq 35 \%$ and $\leq 70 \%$ of predicted. Participants were excluded if they had smoked tobacco within 6 months prior to the start of the study, had undergone lung transplantation, lobectomy or lung volume reduction therapy, or had selective IgA deficiency.

CT scanning was performed using a standardized CT acquisition protocol, optimized for lung densitometry, at total lung capacity (TLC) and functional residual capacity (FRC), where only the TLC scan was used for the current study [17].

\section{Validation}

To validate the method in terms of (regional) structurefunction relationship [30], the Spearman correlation was studied between standard mass score and $\mathrm{D}_{\mathrm{LCO}}$ percent predicted values, and $\mathrm{FEV}_{1}$ percent predicted from the AATD patient group, respectively. The agreement in separation into normal and abnormal lung structure or gas exchange was assessed by kappa-statistics. In this separation, SMS values less than -2 were considered abnormal, and for $\mathrm{D}_{\mathrm{LCO}}$ a threshold of $80 \%$ of predicted values was used to define the lower limit of the normal range. A significance level of 0.05 was used for all statistical tests.

As an internal validation using the control data, a leave-one-out cross-validation experiment was performed, where the normalization was determined with $n-1$ controls and tested on one, with n-1 different combinations.

The distribution of SMS values across the basal, central and apical regions was used to distinguish between different subgroups in the RAPID study population.
Subsequently the differences in $\mathrm{D}_{\mathrm{LCO}}$ \%pred between these subgroups was tested.

\section{Results}

The correlations of SMS with the \%-predicted values for $\mathrm{D}_{\mathrm{LCO}}$ and $\mathrm{FEV}_{1}$ are presented in Fig. 2. The correlation with $\mathrm{D}_{\mathrm{LCO}}$ was moderate, but statistically significant $\left(\mathrm{R}^{2}=0.25\right.$, $p<<0.001)$; and for $\mathrm{FEV}_{1}$ the correlation was weak, $\mathbf{R}^{2}=0.048(p=0.003)$. For comparison, the correlation between the \%-predicted values for $\mathrm{D}_{\mathrm{LCO}}$ and $F V_{1}$ was statistically significant but also weak, $R^{2}=0.1202$, $p<<0.001$. For the apical, central and basal regions the correlations between $\mathrm{D}_{\mathrm{LCO}}$ \%pred and SMS values are shown in Fig. 3. It was noted that there were three patients with exceptionally low $\mathrm{D}_{\mathrm{LCO}} \%$ pred values below $10 \%$, which we considered to be likely outliers. Since omitting these values did not considerably change the correlation between SMS and $\mathrm{D}_{\mathrm{LCO}} \%$ pred $\left(\mathrm{R}^{2}=0.26, p<<0.001\right)$, it was decided to preserve these data.

The agreement between global SMS and $\mathrm{D}_{\mathrm{LCO}}$ \%pred in distinguishing abnormal structure or function is presented as a confusion matrix in Table 2. The kappa-statistic showed a fair agreement between SMS and $\mathrm{D}_{\mathrm{LCO}} \%$ pred $(\mathrm{\kappa}=0.252, p<0.001)$, varying from $\mathrm{\kappa}=0.138$ to $\mathrm{k}=0.219$ and $0.264(\mathrm{p}<0.001)$, in the apical, central and basal region, respectively.

From the cross-validation with normal controls, we found that the average SMS value of unseen controls was -0.05 , with a standard deviation of 1.03 , closely corresponded to the targeted mean and standard deviation of 0 and 1 , respectively.

Analyzing the frequency of occurrence of the SMS values below normal across the different lung regions
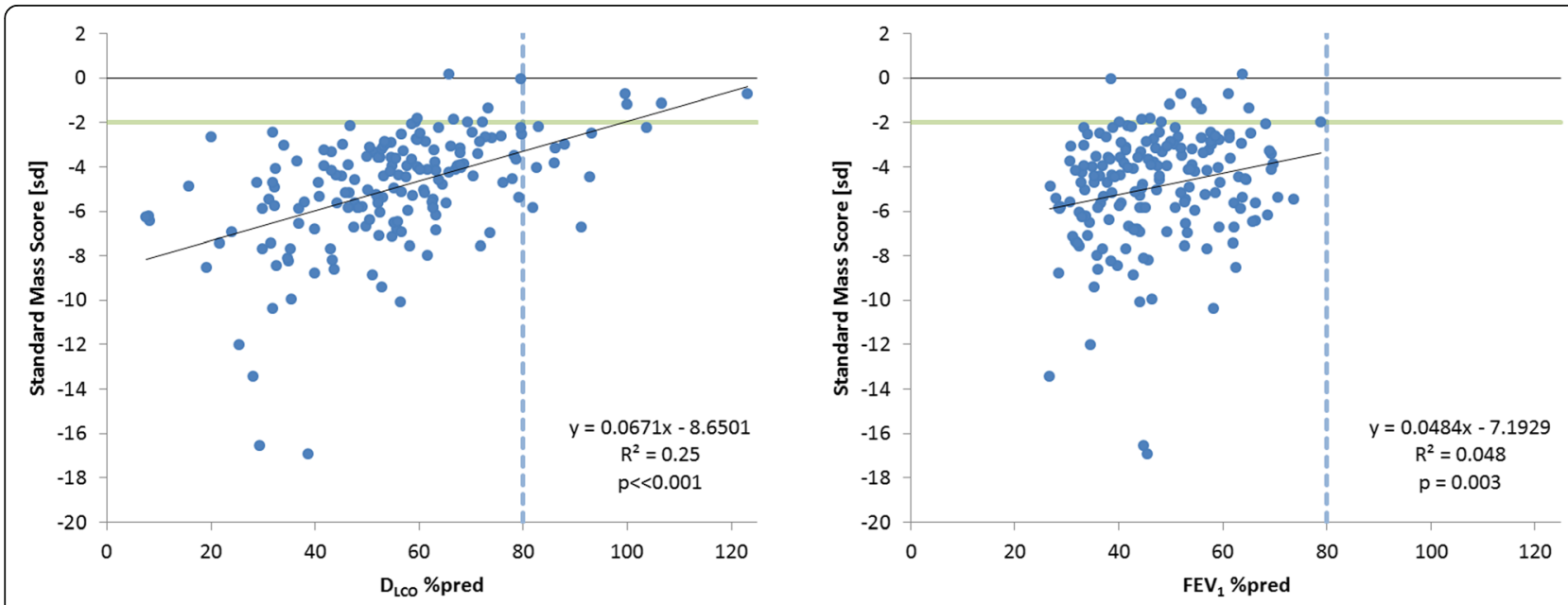

Fig. 2 Relation between standard mass score and percent predicted values for $D_{L C O}$ and FEV $V_{1}$. The green horizontal line indicates the lower limit

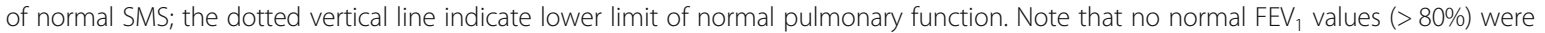

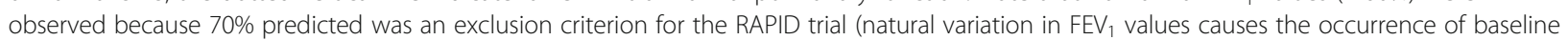
values above the exclusion criterion) 

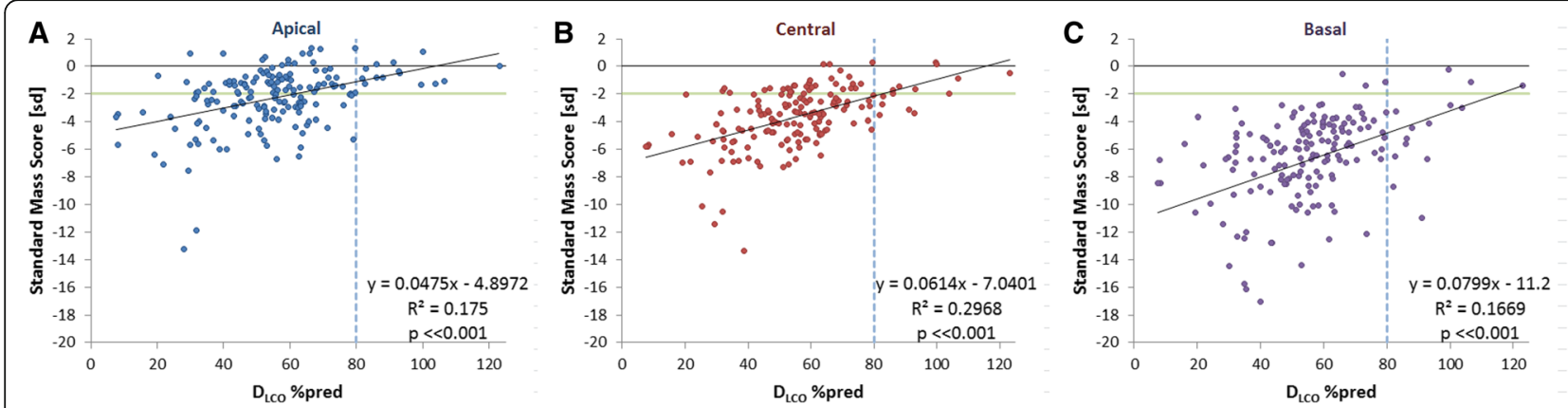

Fig. 3 Correlations between SMS and DLCo\%pred in: a. Apical; b. Central; and c. Basal region. The green horizontal line indicates the lower limit of normal SMS; the dotted vertical line indicate lower limit of normal pulmonary function

(apical, central, basal) in the AATD population revealed that from the eight possible pattern combinations only four predominantly occur, as shown in Fig. 4. In this figure, green regions represent normal lung mass, and red regions indicate SMS values below normal. In $4 \%$ of cases, the lungs actually had normal tissue mass, where the frequency of occurrence increases as the basal, central and apical regions become incrementally involved.

The association between subgroups and $\mathrm{D}_{\mathrm{LCO}}$ \%pred is shown in Fig. $5\left(R^{2}=0.16, p<<0.001\right)$. The range in $\mathrm{D}_{\mathrm{LCO}} \%$ pred was more comparable between the different subgroups in Fig. 5, than for the global SMS scores from Fig. 2, where the range in $\mathrm{D}_{\mathrm{LCO}} \%$ pred was greater in the higher SMS scores.

\section{Discussion}

The accepted principles of standard procedures for the measurement of pulmonary function also apply to lung densitometry, and require the use of the same equipment, preferably the same technician, the same protocol, an appropriate calibration, correction for uncontrolled covariates and a suitable reference to normal values. Most of these issues have been addressed in the research efforts of the past decades [26, 27, 31, 32] and, consequently, CT densitometry has been accepted as the primary outcome parameter in trials evaluating new drugs for pulmonary emphysema [33]. However, the variability between CT scanners and a lack of normative data has hampered its application in clinical practice [23]. In the present study, we have established an initial step in this process, by proposing a method to standardize between CT scanners, in combination with a correction for

Table 2 Confusion matrix, SMS versus $D_{\subset \perp \circ} \%$ pred

\begin{tabular}{lllll}
\hline & & \multicolumn{2}{l}{ D LCO $\%$ pred } & \\
\cline { 3 - 4 } & & normal & abnormal & Total \\
\hline Standard Mass Score & normal & 4 & 10 & 14 \\
& abnormal & 8 & 151 & 159 \\
$\kappa=0.252, p<0.001$ & Total & 12 & 161 & 173 \\
\hline
\end{tabular}

volume differences and a subsequent comparison with a normal database.

Demonstration of the large differences in standard mass score between emphysema patients and normal controls of more than 10 SD (see Fig. 2), and the stronger correlation between SMS and $\mathrm{D}_{\mathrm{LCO}}$, than between $\mathrm{D}_{\mathrm{LCO}}$ and $\mathrm{FEV}_{1}$, supports the application of CT lung densitometry in clinical practice. The future acquisition of a more extensive normal database would provide even greater confidence and support for the use of CT lung densitometry in routine clinical practice.

From the analysis of the normal database, we found that percentile density was not influenced by gender and age, which supports the data of Gevenois et al. [34], who studied the influence of different factors on the mean lung density in 42 healthy subjects. Therefore, any differences in lung density between genders should be interpreted with caution, since the difference is more likely to be a direct consequence of the gender-associated differences in lung size. Gevenois and colleagues [34] did find a slight influence of age on the relative area of low attenuation or 'voxel index' (which is an alternative measure to the percentile density method). However, this influence may also be explained by differences in lung size.

The first study in which normative density data were presented was by Kalender et al. [35], where spirometrically controlled CT data from 52 healthy subjects was analyzed. The mean lung density was calculated from three single slices and used as reference data. They concluded that spirometric control proved difficult even in cooperative patients, preventing an objective comparison with normal controls. Marsh et al. [36] compared CT densitometry from 22 emphysema patients with a normal database of 185 normal subjects, and found a poor discriminating ability of the relative area. However, both studies employed single slice protocols so that the lung volume during scanning could not be measured and a posteriori volume correction was therefore not possible. Heussel et al. [37] compared patients with COPD and 


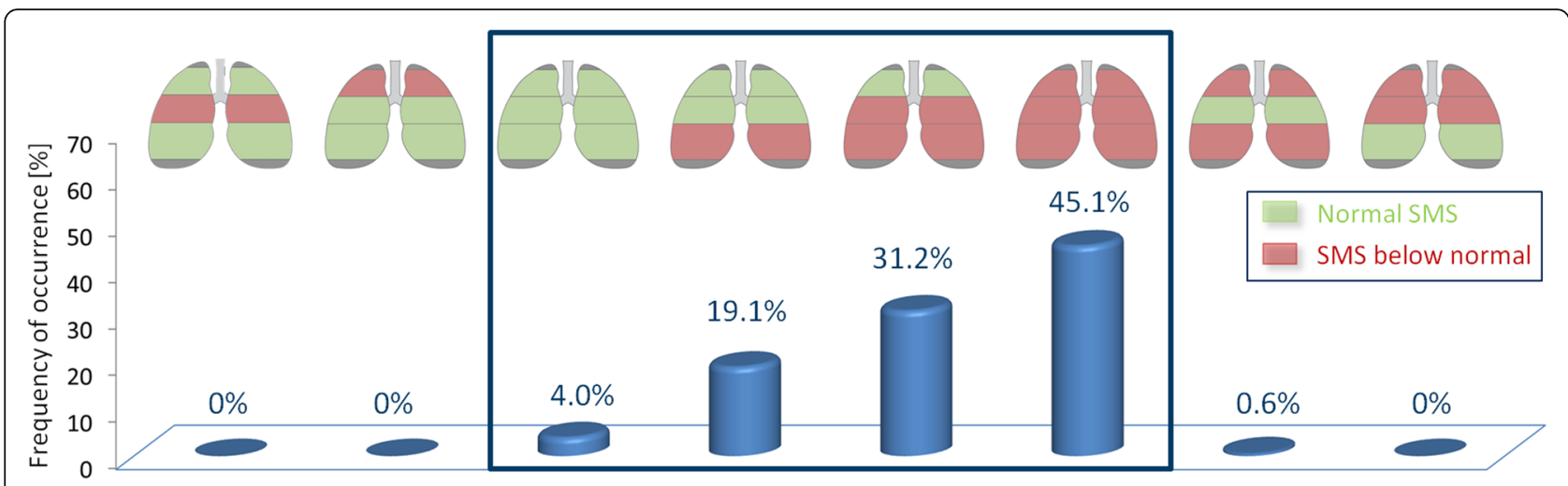

Fig. 4 Bar plot of the frequency of occurrences of all possible combinations of normal and below-normal tissue mass, over the three different regions. Only a subgroup of four possible combinations predominantly occur in practice, as highlighted by the rectangular overlay

interstitial lung disease, employing 44 patients with COPD GOLD stage 0 used as normal data, and concluded that a 15th percentile density higher than -950 HU should be considered normal. More recently, Mets et al. [38] and Pompe et al. [39] presented normal ranges for the 15th percentile density from a cohort of 70 young male divers with above-normal spirometry and of 250 current or former male smokers with normal gas transfer, respectively. In the above studies, no volume correction or standardization was applied, even though volumetric data was available, thereby hampering interpretation and comparison with our data.

Some limitations apply to the current study, and refinements of the methods may still be needed. The recalibration method may be too simple to reflect all potential differences between scanners, such as difference in image reconstruction, different degrees in beam hardening effects and subsequent correction. Alternative methods for performing recalibration have been proposed in the literature, including the use of dedicated lung phantoms [40] or

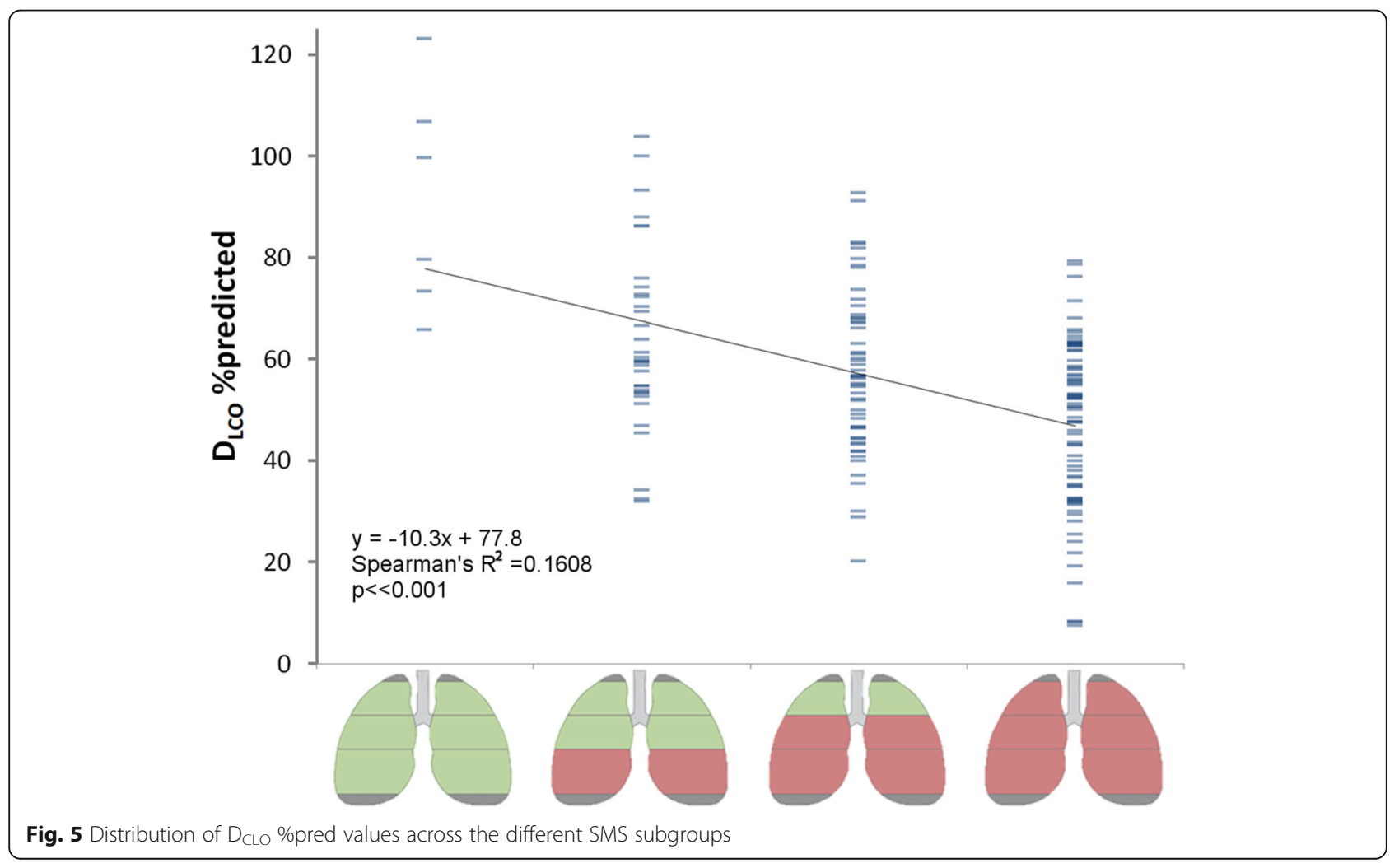


by the normalization of the entire appearance of the CT scans based on frequency band decomposition [41]. This latter method requires, however, that different reconstructions from the same patient are available to obtain the normalization function, which limits its practical implementation. Further standardization of CT image reconstruction is still required to make lung densitometry even more accurate. Therefore, the initiative of the scientific advisory board of the Radiological Society of North America (RSNA) to establish CT standardization, as part of the "Quantitative Imaging Biomarker Alliance" (QIBA) is essential for further acceptance of CT densitometry as a clinical tool [42].

The size of the normal database used here is limited because, for ethical reasons, we were only able to scan patients in this cohort if they were considered at risk for pulmonary metastases. Therefore, the collection of normal values took a long time period and, consequently, the scanner used to develop this data is no longer 'state-of-the-art'. Notwithstanding this potential limitation, there is no indication that older CT scanners produce less accurate densitometric results than modern scanners. Further multi-center studies are needed to extend this database and produce more relevant standard scores for emphysema, possibly involving more explanatory variables in the statistical model. For example, smoking status is a known factor influencing lung density in a group of 463 COPD patients [43], and may need to be included in the model.

Nevertheless, the requirements for the highest degree of precision are less important for cross-sectional studies compared to longitudinal studies of potential disease modifying treatment effects. However, simple application and refinement of the current methodology will facilitate such studies.

The presented method enabled also a regional analysis of lung tissue mass compared to normal tissue, in a representative sample of patients with severe AATD. The finding that only four subgroups exist based on their regional SMS patterns suggests that emphysema in AATD develops from basal to global destruction of lung tissue, which needs to be confirmed in longitudinal studies.

\section{Conclusions}

The standardization and normalization of lung mass values has been shown to be feasible. Consequently, the methodology could be used in clinical practice in the near future, although further refinement of the standardization methods may be needed, either by a posteriori recalibration or by a standardized protocol for different CT manufacturers. The adoption of these principles may improve the application of lung CT densitometry as a research and clinical tool where information about distribution of emphysema is required for the purpose of clinical decision making.

\section{Endnotes}

${ }^{1}$ The 15 th percentile density was chosen over mean lung density (MLD), since densities are not normally distributed and MLD is more prone to outliers from the segmentation, affecting its reproducibility [44, 45].

\section{Additional file}

Additional file 1: Individual data from the normal database. (XLSX $13 \mathrm{~kb}$ )

\section{Abbreviations}

AATD: Alpha-1 antitrypsin deficiency; COPD: Chronic obstructive pulmonary disease; CT: Computed tomography; DLCO: Diffusing capacity for carbon monoxide; EMA: European medicines agency; FDA: United states food and drug administration; FEV1: Forced expiratory volume in $1 \mathrm{~s}$; FVC: Forced vital capacity; MLD: Mean Lung Density; PD15: 15th Percentile density;

QIBA: Quantitative imaging biomarker alliance; RSNA: Radiological society of North America; SMS: Standard Mass Score; TLC: Total lung capacity;

VA: Alveolar volume

\section{Acknowledgments}

The $C T$ data and pulmonary lung function tests from the RAPID trial were kindly provided by CSL Behring. We would like to thank M. Wencker and O. Vit (CSL Behring, Bern, Switzerland) for their input in the discussions on the results of this study.

\section{Funding}

The authors did not receive any funding for this study.

\section{Availability of data and materials}

The data that support the findings of this study are available from CSLBehring but restrictions apply to the availability of these data, which were used under license for the current study, and so are not publicly available. CSL will consider requests to share Individual Patient Data (IPD) from review groups or bona-fide researchers. IPD requests will be accepted 12 months following publication on a public website. IPD will only be provided for the purposes of meta-analyses. The proposed use of the IPD will be reviewed by an internal CSL review committee. If the request is approved and the researcher agrees to the terms and conditions, IPD that has been appropriately anonymized will be available. The IPD will then be available to the researcher for 2 years. Supporting documents including study protocol and Statistical Analysis Plan will also be provided.

All data analysed from the normal database are included in this published article and its supplementary information files.

\section{Authors' contributions}

BCS designed the method for normalization and its evaluation, drafted the manuscript, contributed in the interpretation of the results. He agreed to be accountable for this work in assuring accuracy and integrity.

JS was involved in the design and evaluation, acquisition of data and interpretation of the results. He was involved in drafting and critically revising the manuscript, giving final approval of the version to be published. MEB was involved in performing the image analysis of the normal database, and was involved in drafting and interpreting the results. She critically revising the manuscript and approved the version to be published. DGP was involved in design of the method and analysis and interpretation of the results. He was involved in drafting and critically revising the manuscript, and approved the version to be published. All authors read and approved the final manuscript.

\section{Ethics approval and consent to participate}

For the RAPID trial, all patients provided written informed consent and approval from all local institutional review boards participating in the trial was obtained. For the normal database, all subjects included were asked to participate in the study and gave written informed consent. Approval for the study was obtained from the ethical board of LUMC. 


\section{Consent for publication}

Not applicable

\section{Competing interests}

BCS is consultant for CSL-Behring and BioClinica, the contract research organization that performed the lung densitometry for the RAPID trial. JS received funding for projects from CSL Behring and Kamada. MEB does not have competing interest.

DGP has received lecture fees, served on Advisory Boards and provided independent consultancy services to CSL Behring.

\section{Publisher's Note}

Springer Nature remains neutral with regard to jurisdictional claims in published maps and institutional affiliations.

\section{Author details}

'Division of Image Processing, Department of Radiology, Leiden University Medical Center, Leiden, The Netherlands. ${ }^{2}$ Department of Pulmonology, Leiden University Medical Center, Leiden, The Netherlands. ${ }^{3}$ Department of Respiratory Medicine, University Hospitals of Coventry and Warwickshire, Clifford Bridge Road, Coventry, UK.

\section{Received: 12 November 2018 Accepted: 20 February 2019} Published online: 28 February 2019

\section{References}

1. Barnes PJ. GOLD 2017: a new report. Chest. 2017;151:245-6.

2. Gibson GJ, Geddes DM, Costabel U, Sterk PJ, Corrin B. Respir Med W. B. Saunders. 2003.

3. Stolk J, Stockley RA, Piitulainen E, Stoel BC. Relationship between change in lung density and long-term progression of lung function. Am J Respir Crit Care Med. 2015;192:114-6.

4. Snider GL, K J, Thurlbeck WM, Bengali ZH. the definition of emphysema. Report of a National Heart, Lung, and Blood Institute, division of lung diseases workshop. Am Rev Respir Dis. 1985;132:182-5.

5. Hayhurst MD, MacNee W, Flenley DC, Wright D, McLean A, Lamb D, Wightman AJ, Best J. Diagnosis of pulmonary emphysema by computerised tomography. Lancet. 1984;2:320-2.

6. Wegener $\mathrm{OH}$, Koeppe $\mathrm{P}$, Oeser $\mathrm{H}$. Measurement of lung density by computed tomography. JComputAssistTomogr. 1978;2:263-73.

7. Bankier AA, de Maertelaer $V$, Keyzer C, Gevenois PA. Pulmonary emphysema: subjective visual grading versus objective quantification with macroscopic morphometry and thin-section CT densitometry. Radiology. 1999;211:851-8.

8. Gevenois PA, DeVuyst P, deMaertelaer V, Zanen J, Jacobvitz D, Cosio MG, Yernault JC. Comparison of computed density and microscopic morphometry in pulmonary emphysema. Am J Respir Crit Care Med. 1996; 154:187-92.

9. Gould GA, MacNee W, McLean A, Warren PM, Redpath A, Best JJ, Lamb D, Flenley DC. CT measurements of lung density in life can quantitate distal airspace enlargement--an essential defining feature of human emphysema. Am Rev Respir Dis. 1988;137:380-92.

10. Dowson LJ, Newall C, Guest PJ, Hill SL, Stockley RA. Exercise capacity predicts health status in alpha(1)-antitrypsin deficiency. Am J Respir Crit Care Med. 2001;163:936-41.

11. Gould GA, Redpath AT, Ryan M, Warren PM, Best JJ, Flenley DC, MacNee W. Lung CT density correlates with measurements of airflow limitation and the diffusing capacity. Eur Respir J. 1991;4:141-6.

12. Stolk J, Ng WH, Bakker ME, Reiber JHC, Rabe KF, Putter H, Stoel BC. Correlation between annual change in health status and computer tomography derived lung density in subjects with alpha(1)-antitrypsin deficiency. Thorax. 2003;58:1027-30.

13. Parr DG, Stoel BC, Stolk J, Stockley RA. Validation of computed tomographic lung densitometry for monitoring emphysema in alpha1-antitrypsin deficiency. Thorax. 2006;61:485-90.

14. Stolk J, Putter H, Bakker EM, Shaker SB, Parr DG, Piitulainen E, Russi EW, Grebski E, Dirksen A, Stockley RA, et al. Progression parameters for emphysema: a clinical investigation. Respir Med. 2007;101:1924-30.

15. Dawkins PA, Dowson LJ, Guest PJ, Stockley RA. Predictors of mortality in alpha1-antitrypsin deficiency. Thorax. 2003;58:1020-6.

16. Chapman KR, Burdon JG, Piitulainen E, Sandhaus RA, Seersholm N, Stocks JM, Stoel BC, Huang L, Yao Z, Edelman JM, McElvaney NG. Intravenous augmentation treatment and lung density in severe alpha1 antitrypsin deficiency (RAPID): a randomised, double-blind, placebo-controlled trial. Lancet. 2015;386:360-8.

17. McElvaney NG, Burdon J, Holmes M, Glanville A, Wark PA, Thompson PJ, Hernandez P, Chlumsky J, Teschler H, Ficker JH, et al. Long-term efficacy and safety of alpha1 proteinase inhibitor treatment for emphysema caused by severe alpha1 antitrypsin deficiency: an open-label extension trial (RAPID-OLE). Lancet Respir Med. 2017;5:51-60.

18. Summary of the European public assessment report (EPAR) for Respreeza [https://www.ema.europa.eu/medicines/human/EPAR/respreeza].

19. Parr DG, Dirksen A, Piitulainen E, Deng C, Wencker M, Stockley RA. Exploring the optimum approach to the use of $\mathrm{CT}$ densitometry in a randomised placebo-controlled study of augmentation therapy in alpha 1-antitrypsin deficiency. Respir Res. 2009;10:75.

20. Bakker ME, Putter H, Stolk J, Shaker SB, Piitulainen E, Russi EW, Stoel BC. Assessment of regional progression of pulmonary emphysema with $C T$ densitometry. Chest. 2008;134:931-7.

21. Parr DG, Sevenoaks M, Deng C, Stoel BC, Stockley RA. Detection of emphysema progression in alpha 1-antitrypsin deficiency using CT densitometry; methodological advances. Respir Res. 2008;9:9-12.

22. Stoel BC, Stolk J. Optimization and standardization of lung densitometry in the assessment of pulmonary emphysema. Investig Radiol. 2004;39:681-8.

23. Stolk J, Stoel BC. Lung densitometry to assess progression of emphysema in chronic obstructive pulmonary disease: time to apply in the clinic? Am J Respir Crit Care Med. 2011;183:1578-80.

24. Stolk J, Versteegh MI, Montenij LJ, Bakker ME, Grebski E, Tutic M, Wildermuth S, Weder W, el Bardiji M, Reiber JH, et al: Densitometry for assessment of effect of lung volume reduction surgery for emphysema. Eur Respir J 2007, 29:1138-1143.

25. Parr DG, Stoel BC, Stolk J, Nightingale PG, Stockley RA. Influence of calibration on densitometric studies of emphysema progression using computed tomography. Am J Respir Crit Care Med. 2004;170:883-90.

26. Shaker SB, Dirksen A, Laursen LC, Skovgaard LT, Holstein-Rathlou NH. Volume adjustment of lung density by computed tomography scans in patients with emphysema. Acta Radiol. 2004;45:417-23.

27. Stoel BC, Putter H, Bakker ME, Dirksen A, Stockley RA, Piitulainen E, Russi EW, Parr D, Shaker SB, Reiber JH, Stolk J. Volume correction in computed tomography densitometry for follow-up studies on pulmonary emphysema. ProcAmThoracSoc. 2008;5:919-24.

28. Staring M, Bakker ME, Stolk J, Shamonin DP, Reiber JHC, Stoel BC. Towards local progression estimation of pulmonary emphysema using CT. Med Phys. 2014;41:021905.

29. Quanjer PH, Tammeling GJ, Cotes JE, Pedersen OF, Peslin R, Yernault JC. Lung volumes and forced ventilatory flows. Report Working Party Standardization of Lung Function Tests, European Community for Steel and Coal Official Statement of the European Respiratory Society. Eur Respir J Suppl. 1993;16:5-40.

30. Parr DG, Stoel BC, Stolk J, Stockley RA. Pattern of emphysema distribution in alpha1-antitrypsin deficiency influences lung function impairment. Am J Respir Crit Care Med. 2004;170:1172-8.

31. Parr DG, Stockley RA. Standardization of CT densitometry. Radiology. 2004; 230:887.

32. Stoel BC, Bode F, Rames A, Soliman S, Reiber JH, Stolk J. Quality control in longitudinal studies with computed tomographic densitometry of the lungs. ProcAmThoracSoc. 2008:5:929-33.

33. FDA Blood Products Advisory Committee 95th Meeting July 20-21 2009 [https://wayback.archive-it.org/7993/20170113022628/http://www.fda.gov/ downloads/AdvisoryCommittees/CommitteesMeetingMaterials/ BloodVaccinesandOtherBiologics/BloodProductsAdvisoryCommittee/ UCM171091.pdf].

34. Gevenois PA, Scillia P, de Maertelaer V, Michils A, De Vuyst P, Yernault JC. The effects of age, sex, lung size, and hyperinflation on CT lung densitometry. AJR Am J Roentgenol. 1996;167:1169-73.

35. Kalender W, Fichte H, Bautz W, Zwick A, Rienmuller R, Behr J, van Engelshoven JM, Lamers RJ, Vock P: Reference Values for Lung Density and Structure Measured by Quantitative CT. In Advances in CT III. Edited by H P, G L. Vienna: Springer-Verlag; 1994. p. 290-7.

36. Marsh S, Aldington S, Williams MV, Nowitz MR, Kingzett-Taylor A, Weatherall M, Shirtcliffe PM, McNaughton AA, Pritchard A, Beasley R. Utility of lung density measurements in the diagnosis of emphysema. Respir Med. 2007; 101:1512-20. 
37. Heussel CP, Herth FJ, Kappes J, Hantusch R, Hartlieb S, Weinheimer O, Kauczor HU, Eberhardt R. Fully automatic quantitative assessment of emphysema in computed tomography: comparison with pulmonary function testing and normal values. Eur Radiol. 2009;19:2391-402.

38. Mets $\mathrm{OM}$, van Hulst RA, Jacobs C, van Ginneken B, de Jong PA. Normal range of emphysema and air trapping on CT in young men. AJR Am J Roentgenol. 2012;199:336-40.

39. Pompe E, van Rikxoort EM, Schmidt M, Ruhaak J, Estrella LG, Vliegenthart $R$, Oudkerk M, de Koning HJ, van Ginneken B, de Jong PA, et al. Parametric response mapping adds value to current computed tomography biomarkers in diagnosing chronic obstructive pulmonary disease. Am J Respir Crit Care Med. 2015;191:1084-6.

40. Subramanian DR, Gupta S, Burggraf D, Vom Silberberg SJ, Heimbeck I, Heiss-Neumann MS, Haeussinger K, Newby C, Hargadon B, Raj V, et al. Emphysema- and airwaydominant COPD phenotypes defined by standardised quantitative computed tomography. Eur Respir J. 2016;4:92-103.

41. Gallardo-Estrella L, Lynch DA, Prokop M, Stinson D, Zach J, Judy PF, van GB, van Rikxoort EM. Normalizing computed tomography data reconstructed with different filter kernels: effect on emphysema quantification. Eur Radiol. 2016;26:478-86.

42. Lung Density Biomarker Committee [http://qibawiki.rsna.org].

43. Grydeland TB, Dirksen A, Coxson HO, Pillai SG, Sharma S, Eide GE, Gulsvik A, Bakke PS. Quantitative computed tomography: emphysema and airway wall thickness by sex, age and smoking. EurRespirJ. 2009;34:858-65.

44. Stoel BC, Vrooman HA, Stolk J, Reiber JH. Sources of error in lung densitometry with CT. Investig Radiol. 1999;34:303-9.

45. Stolk J, Dirksen A, van der Lugt AA, Hutsebaut J, Mathieu J, de Ree J, Reiber $\mathrm{JH}$, Stoel BC. Repeatability of lung density measurements with low-dose computed tomography in subjects with alpha-1-antitrypsin deficiencyassociated emphysema. Investig Radiol. 2001;36:648-51.

Ready to submit your research? Choose BMC and benefit from:

- fast, convenient online submission

- thorough peer review by experienced researchers in your field

- rapid publication on acceptance

- support for research data, including large and complex data types

- gold Open Access which fosters wider collaboration and increased citations

- maximum visibility for your research: over $100 \mathrm{M}$ website views per year

At $\mathrm{BMC}$, research is always in progress.

Learn more biomedcentral.com/submissions 